\title{
IMPUTABILIDAD Y TRASTORNO POR DÉFICIT DE ATENCIÓN E HIPERACTIVIDAD
}

\section{DAVID LORENZO MORILLAS FERNÁNDEZ}

Profesor Titular de Derecho Penal y Criminología

Universidad de Murcia

Email:davidm@um.es

Resumen: El presenta artículo trata de delimitar los efectos producidos en la imputabilidad de las personas que presentan TDAH y desarrollan un comportamiento delictivo, toda vez que semejante hipótesis no ha sido desarrollada por la doctrina científica y los Tribunales de Justicia han ido acotando soluciones parciales al respecto sin existir una línea aplicativa común.

Palabras clave: Trastorno por déficit de atención e hiperactividad, imputabilidad, doctrina, Tribunales de Justicia.

\begin{abstract}
The aim of the following article is focused on effects that criminal liability could be have in person with a diagnosis of ADHD when an antisocial behaviour takes place attending to the fact that neither the main Scientific Doctrine nor the Justice Courts have been able to find common solutions, much of them partial but without any uniform jurisprudential treatment.
\end{abstract}

Key words: Attention-Deficit /Hiperactivity Disorder (ADHD), Criminal liability, Doctrine, Justice Courts.

SUMARIO: I. IDENTIFICACIÓN DEL TRASTORNO. 1. Introducción. 2. Concepto y características. 3. Tipologías. II. INCIDENCIA DEL TDAH EN LA IMPUTABILIDAD. 1. Fijación de la cuestión. 2. Respuestas dadas por la Jurisprudencia. 2.1. Tribunal Supremo. 2.2. Audiencias Provinciales. 3. Conclusiones. 


\section{IDENTIFICACIÓN DEL TRASTORNO}

\section{Introducción.}

El trastorno por déficit de atención e hiperactividad, más conocido socialmente por su anagrama TDAH, constituye uno de los trastornos que más interés ha despertado en la comunidad científica en los últimos años. Cada vez existen mayores estudios e investigaciones desde un amplísimo sector científico -Psicología, Medicina, Trabajo Social (...)- que intentan buscar pautas de control o explicación a determinados comportamientos desarrollados tanto por menores como por adultos y que, en no pocas ocasiones, devienen en actitudes ilícitas que el propio individuo no puede evitar pese a conocer su ilicitud.

Así pues, pese a que se trata de una realidad propia del siglo XXI, de cara a la sociedad, lo cierto es que el trastorno ha estado muy presente a lo largo de la historia si bien ha pasado completamente desapercibido bajo las clásicas explicaciones asociadas a comportamientos de menores excesivamente inquietos o en constante movimiento, cuando en realidad se trata de un trastorno lo que motiva semejante hiperactividad. En este sentido, a modo de ejemplo, puede datarse en 1865 como la fecha en la que el Dr. Heinrich Hoffman menciona por primera vez la existencia del citado trastorno; 1902 cuando los doctores Still y Tredgold describen por primera vez sus síntomas, siquiera asociándolos a un defecto del control moral; o en 1980 cuando existe el primer reconocimiento a nivel oficial e internacional ${ }^{1}$, al incluirse el trastorno por déficit de atención en el DSM-III².

\footnotetext{
${ }^{1}$ No obstante, el DSM-II introdujo la categoría "reacción hipercinética de la infancia".

${ }^{2}$ Vid., más ampliamente, GRATCH, L., El trastorno por déficit de atención (DD-ADHD). Clínica, diagnóstico y tratamiento en la infancia, la adolescencia y la adultez, Buenos Aires, págs. 19-22; SAN SEBÁSTIÁN CABASÉS, J., SOUTULLO ESPERÓN, C. y FIGUEROA QUINTANA, A., «Trastorno
} 
Es tal la dimensión social generada y las repercusiones que conlleva que, según la Asociación Americana de Psiquiatría, entre un tres y un siete por ciento de los niños lo presenta, si bien, investigaciones más reciente, como pueden ser, por ejemplo, la llevada a cabo por Setlik, Bond y Ho, lo vienen situando en una horquilla del 8-12\%, siendo más habitual en la población masculina -en torno al $80 \%$ de los casos lo presentan varones ${ }^{3}$-. Por el contrario, las tasas en adultos son más bajas, debido principalmente a la intervención y detección a edades tempranas, situándose en torno al $4 \%{ }^{4}$, si bien el DSM-5 refiere, por primera vez, el porcentaje de representatividad en adultos, concretándolo en un $2,5 \%^{5}$, una tasa inferior a la que venía refiriendo la doctrina especializada. En el caso de España, no existen unos parámetros medidores claros pero debe estimarse que la afectación gira en torno al 5-8\% de la población, encontrándose la principal prevalencia entre los seis y los nueve años de edad ${ }^{6}$.

Un dato muy ilustrativo que puede ayudar a entender la dimensión del trastorno, viene puesto de manifiesto por la revisión bibliográfica llevada a cabo por Hechtman donde vislumbra tres subgrupos diferentes en la evolución del TDAH en la edad adulta para los niños hiperactivos: i) pacientes con pocos problemas; ii) pacientes que siguen teniendo síntomas del síndrome y problemas sociales, emocionales y laborales asociados - la mayoría de hiperactivos se integra en este grupo-; y iii) pacientes con trastornos antisociales y/o psiquiátricos significativos -una proporción relativamente pequeña de la población adulta hiperactiva- ${ }^{7}$.

por déficit de atención e hiperactividad», en Soutullo Esperón y Mardomingo Sanz (Coord.), Manual de Psiquiatría del Niño y del Adolescente, Madrid, 2010, pág. 55.

${ }^{3}$ Hay investigaciones que reducen semejante porcentaje si bien la esfera mínima de representatividad de los varones del $60 \%$ frente al $40 \%$ de las mujeres. Véase, a modo de ejemplo, Rettew D. y Hudziak, J., «Genética del TDAH», en Brown (Dir.), Comorbilidades del TDAH, Barcelona, 2010, pág. 29.

${ }^{4}$ SETLIK, J., BOND, R. Y HO, M., «El abuso de los medicamentos de prescripción para el TDAH por los adolescentes está aumentando al mismo ritmo que las prescripciones de estos medicamentos», en Pediatrics, $n^{o}$ 68, 2009, pág. 123. Recurso electrónico disponible en: http://www.elsevier.es/en/node/2079958

5 AMERICAN PSYCHIATRIC ASSOCIATION (APA), Diagnostic and Statistical Manual of Mental Disorders, Fifth Edition (DSM-5), Washington, D.C., 2013, pág.61.

6 SAN SEBÁSTIÁN CABASÉS, J., SOUTUllO ESPERÓN, C. y FIGUEROA QUINTANA, A., «Trastorno.... cit., pág. 56.

${ }^{7}$ HECHTMAN, L., «TDAH en adultos», en Brown (Dir.), Comorbilidades ... cit., pág. 86. 
Sus efectos son muy diversos si bien, como ha compilado Gratch, los sujetos que lo presentan manifiestan dificultades para la concentración y el mantenimiento de la atención, pudiendo destacar las siguientes: i) realistas (lugares ruidosos, etc); ii) neuróticas (por ejemplo, neurosis obsesiva); iii) fisiopatológicas (intoxicaciones o patologías neurológicas); y iv) secundarias (trastornos metabólicos o anemia) ${ }^{8}$. Sin embargo, como muy bien han referido López Soler, Castro Sáez, Isabel Belchí y Romero Medina, el problema se pone de manifiesto por una deficiencia en la capacidad para inhibir y supervisar al mismo tiempo las conductas, y por la dificultad para poner freno a las distracciones (défict de atención), a los pensamientos y actividad (impulsividad) y a los movimientos y acción constante (hiperactividad) ${ }^{9}$.

Sea como fuere, lo que también debe tenerse muy presente, aumentando el grado de dificultad en el diagnóstico del TDAH, son las comorbilidades, en el sentido de que es bastante frecuente que existan otros trastornos psiquiátricos, neurológicos o, en términos genéricos, médicos. En este sentido, como han referido expresamente San Sebastián Cabasés, Soutullo Esperón y Figueroa Quintana, en torno al 70\% de los pacientes con TDAH presentan al menos un trastorno psiquiátrico asociado $\mathrm{y}$ aproximadamente el $40 \%$ sufren al menos dos, complicando en exceso este hecho su diagnóstico, empeorando la evolución y la respuesta al tratamiento. Entre las mismas pueden referirse, a título orientativo, las generadas con trastornos del estado de ánimo, de ansiedad, negatividad y agresividad, obsesivo-compulsivo, del lenguaje y/o del aprendizaje, consumo de tóxicos, del sueño, síndrome de Tourette $(\ldots)^{10}$.

\footnotetext{
${ }^{8}$ GRATCH, L., El trastorno por déficit de atención (DD-ADHD). Clínica, diagnóstico y tratamiento en la infancia, la adolescencia y la adultez, Buenos Aires, pág. 10.

9 LÓPEZ SOLER, C., CASTRO SÁEZ, M., ISABEL BELCHÍ, A. y ROMERO MEDINA, A., «Descripción clínica: El trastorno por déficit de atención e hiperactividad y los trastornos de comportamiento perturbador», en López Soler y Romero Medina, Trastorno por Déficit de Atención e Hiperactividad y Trastornos Del Comportamiento en la infancia y en la adolescencia: Clínica, Diagnóstico, Evaluación y Tratamiento, Madrid, 2013, pág. 12.

10 Sobre el contenido de cada una de estas comorbilidades puede consultarse BROWN, T., Comorbilidades del TDAH, Barcelona, 2010, págs. 97-316.
} 


\section{Concepto y características.}

El DSM-IV-TR ha definido el trastorno por déficit de atención e hiperactividad como aquel «trastorno neuroconductual que se exterioriza en la infancia, asociado a una falta de atención, hiperactividad e impulsividad que se exterioriza en las relaciones del individuo con la sociedad».

De conformidad con lo anterior, cabría subrayar cuatro grandes características identificativas del citado trastorno:

A) Se trata de un trastorno neuroconductual. Al igual que sucede con los estudios pioneros en cualquier tipo de trastorno o enfermedad, las primeras investigaciones asociadas al TDAH vinculaban su presencia a situaciones carentes hoy día de todo tipo de fundamento, como, por ejemplo, problemas familiares, lesiones en la cabeza, daños cerebrales ${ }^{11}$, intoxicación crónica con plomo, alto consumo de conservantes en los alimentos ${ }^{12}$ (...) si bien la ciencia ha logrado demostrar que semejantes premisas no son ciertas al haberse descrito supuestos diagnosticados en los que no existían antecedentes de ninguna de las causas expuestas.

Desechadas las primeras argumentaciones, el hilo explicativo se redujo hacia la esfera biológica y la incidencia que la genética podría presentar. En este sentido, en la actualidad, existe una opinión muy consolidada de que su origen radica en diversos problemas localizados en determinados neurotransmisores existentes en ciertas partes del cerebro, lo cual origina una inhibición de los impulsos y una ausencia de capacidad para controlar la atención, lo cual puede evidenciarse, y ha quedado perfectamente demostrado gracias a las técnicas de neuroimagen, al comparar las conexiones

11

${ }^{12}$ GRATCH, L., El trastorno ... cit., pág. 23; SAN SEBÁSTIÁN CABASÉS, J., SOUTULLO ESPERÓN, C. y FIGUEROA QUINTANA, A., «Trastorno...» cit., pág. 55. 
cerebrales de niños que presentan TDAH y los que no. Del mismo modo, se ha apreciado que las personas que presentan TDAH poseen una menor cantidad de glucosa en el cerebro. Sin embargo, pese a lo anterior, como afirman San Sebastián Cabasés, Soutullo Esperón y Figueroa Quintana, aún no están del todo claras las causas que lo motivan, pese a tener un origen fundamentalmente biológico, aunque hay una evidente influencia de factores etiológicos genéticos y ambientales que contribuyen a su aparición, llegando a cifrar en un $77 \%$ la incidencia de los primeros ${ }^{13}$.

Gratch prefiere utilizar la terminología "trastorno neuroquímicos" como motivadores, especificando la absoluta relevancia presentada por los neurotransmisores, incluyendo la dopamina, noradrenalina, acetilcolina y serotonina ${ }^{14}$. El sistema límbico y el lóbulo frontal constituyen las principales localizaciones anatómicas del sistema encargado de la atención, función muy importante del Sistema Nervioso Central, cuya participación es imprescindible para el adecuado desarrollo de los procesos de aprendizaje ya que, desde allí, las células nerviosas envían sus proyecciones a diferentes partes del cerebro por lo que la vinculación con las tareas de atención y aprendizaje es un hecho ${ }^{15}$. Así pues, la interrelación de esos grupos neuronales es mediatizada por la intervención de los neurotransmisores con lo que la actividad de la atención requiere una estimulación o inhibición de diferentes áreas del cerebro, no siendo un proceso común o similar en todos los casos sino que variará según la intensidad del proceso a realizar con lo que se exigirá diferentes tipos de atención según la actividad y el comportamiento requerido - piénsese, por ejemplo, en un niño sentado en el colegio en clase prestando atención y ese mismo infante en la clase de educación física desarrollando una actividad-. Ante ello, una persona modula su capacidad de atención y movimiento a la necesidad de la situación concreta pero una con TDAH posee dificultades específicas que exceden a su voluntad, llegando a impedirle poder cumplir

\footnotetext{
${ }^{13}$ SAN SEBÁSTIÁN CABASÉS, J., SOUTULLO ESPERÓN, C. y FIGUEROA QUINTANA, A., «Trastorno.... cit., pág. 55.

${ }^{14}$ Las variaciones en la concentración de los citados neurotransmisores producen diferentes trastornos como, por ejemplo el Parkinson.

${ }^{15}$ De acuerdo con ello, tanto vías aferentes como eferentes influirían en el resultado o manifestación de la sintomatología como reflejo de la responsabilidad del lóbulo frontal en la propia función ejecutiva.
} 
ciertas funciones con la eficacia requerida ${ }^{16}$. Las connotaciones de este postulado son muy relevantes pues, como detallaré posteriormente, admitir esta tesis conlleva ya una declaración fundamental de cara a la imputabilidad del sujeto consistente en la no afectación a la esfera cognitiva del sujeto.

Sin embargo, pese a que semejantes razonamientos pudieran parecer absolutamente innovadores, se trata de una práctica investigadora relativamente habitual en determinados tipos de trastorno y así, por ejemplo, las dos premisas enunciadas son igualmente equiparables a los trastornos de la personalidad y el tratamiento doctrinal y jurisprudencial otorgado al respecto deviene a favor de la plena imputabilidad del sujeto $^{17}$.

Llegados a este punto conviene resaltar las evidencias científicas anteriores, las cuales considero claves para focalizar posteriormente la vinculación del TDAH con la imputabilidad en el sentido de hasta qué punto se le puede exigir a un individuo que no desarrolle un acto impulsivo cuando no tiene las capacidades para controlarlo.

No obstante, lo que sí es hoy día un hecho cierto y validado empíricamente es la incidencia genética en el origen del trastorno, toda vez que, de acuerdo con las investigaciones de San Sebastián Cabasés, Soutullo Esperón y Figueroa Quintana, se ha demostrado que en el $77 \%$ de los casos detectados la causa motivadora del trastorno es genética, estableciéndose, como factor de riesgo, el hecho de que uno de los progenitores lo presente aumenta la probabilidad de aparición en un descendiente de entre dos y ocho veces, quedando el ambiente relegado a un factor desencadenante en niños biológicamente vulnerables o como modulador del curso de la enfermedad -

\footnotetext{
${ }^{16}$ GRATCH, L., El trastorno... cit., pág. 24.

${ }^{17}$ Sobre la imputabilidad de los trastornos de la personalidad vid. JIMÉNEZ DÍAZ, M J. y FONSECA MORALES, G., Trastornos de la personalidad (Psicopatías): Tratamiento científico y jurisprudencial, Madrid, 2007; MORILLAS FERNÁNDEZ, D. L., «Aspectos criminológicos de los psicópatas y asesinos en serie», en Cuadernos de Política Criminal, $n^{\circ}$ 77, Madrid, 2002, págs. 414-417.
} 
empeorando o mejorando el curso clínico- ${ }^{18}$. Así, siguiendo a Biederman y Faraone, los factores ambientales que más pueden incidir son la exposición in utero al tabaco, alcohol o tratamiento farmacológico, prematuridad, bajo peso al nacer, complicaciones perinatales, edad avanzada de la madre en el parto, conflictos familiares severos o crónicos, antecedentes de trastornos psiquiátricos en los padres, haber permanecido institucionalizado e hipoestimulado durante un largo período de tiempo, presentar una gran adversidad psicosocial $(\ldots)^{19}$.

B) Su origen radica en la infancia. Se trata de otro dato perfectamente validado y comprende la aparición de los primeros síntomas antes de los siete años de edad, constituyendo la infancia, niñez o adolescencia el momento a partir del cual la exteriorización es evidente ${ }^{20}$. El DSM-IV es muy claro al respecto y, en este sentido, refiere expresamente como uno de los parámetros a apreciar para su diagnóstico el hecho de que los síntomas causaran alteraciones antes de los siete años de edad. Pese a la citada referencia a ese intervalo de edad, el diagnóstico suele establecerse hoy día, con parámetros generales, en torno a los cuatro o cinco años de edad, constituyendo el límite de los siete un máximo orientativo.

Por ello, recobra una especial importancia la detección del trastorno en sus fases iniciales siendo muy recomendable acotar las medidas necesarias tendentes a acotarlo reduciendo así los efectos que lleva aparejado. Según Gratch, entre el 30 y el 70\% de los niños que han padecido TDAH y cuya sintomatología no remitió en la adolescencia sobrellevarán durante su vida adulta los inconvenientes producidos por el citado trastorno de manera residual ${ }^{21}$.

\footnotetext{
18 SAN SEBÁSTIÁN CABASÉS, J., SOUTULlO ESPERÓN, C. y FIGUEROA QUINTANA, A., «Trastorno.... cit., pág. 62.

${ }^{19}$ BIEDERMAN, J. y FARAONE, S. V., «Attention-deficit hyperactivity disorder», en The Lancet $n^{o}$ 336, 2005, págs. 237-248. Recurso electrónico disponible en: http://www.thelancet.com/journals/lancet/article/PIIS0140-6736(05)66915-2/fulltext\#article upsell SAN SEBÁSTIÁN CABASÉS, J., SOUTULLO ESPERÓN, C. y FIGUEROA QUINTANA, A., «Trastorno.... cit., pág. 63.

${ }^{20}$ DSM-IV TR.

${ }^{21}$ GRATCH, L., El trastorno... cit., pág. 149.
} 
C) Se asocia a una falta de atención, hiperactividad e impulsividad. Obviamente tales parámetros pueden ser observados en no pocos menores y, llegado el caso, adultos, pero de lo que aquí se trata es de evaluar y verificar su existencia en niveles mucho más intensos de lo que podría ser habitual para un individuo medio.

La inatención, como han puesto de manifiesto López Soler, Castro Sáez, Isabel Belchí y Romero Medina, se relaciona con la dificultad para realizar una misma tarea en un período largo de tiempo, no siendo de extrañar que el sujeto se aburra al instante o "se le vaya el santo al cielo" y empiece a pensar en otras cosas; la hiperactividad se vincula a una movilidad excesiva y la rigidez y falta de coordinación en sus movimientos, lo que incide en frecuentes caídas, si bien el constante movimiento en situaciones en las que no tendría que producirse constituye uno de los principales indicadores para su sospecha -al igual que hablar sin parar, dar golpes $(\ldots)^{22}$, aunque, conforme avanzan en edad, la hiperactividad tiende a disminuir aparentemente aunque dirán sentirse inquietos o nerviosos por dentro ${ }^{23}$; mientras que la impulsividad debe asociarse, siguiendo a Gratch, con una incapacidad no premeditada del sujeto para controlar sus actos, llegando a exteriorizarse como agresividad; esto es, el incremento de la tensión se descarga impulsivamente con el objeto de hacer daño o defenderse, si bien se manifiesta de manera distinta según el grado evolutivo del individuo y así, por ejemplo, en la edad escolar es muy frecuente apreciar dificultades en el aprendizaje, en la adolescencia peleas con pares, robos, etc y en la adultez con inestabilidad emocional, fácil irascibilidad y toma rápida de decisiones que requerirían mayor reflexividad ${ }^{24}$.

D) Se exterioriza en las relaciones del individuo con la sociedad. Por la propia esencia del trastorno, tiende a visualizarse de manera más acentuada en esferas ajenas o externas al ámbito doméstico, principalmente cuando existen estímulos externos que

\footnotetext{
${ }^{22}$ En este sentido, creo que resulta muy ilustrativa la referencia hecha por San Sebastián Cabasés, Soutullo Esperón y Figueroa Quintana cuando afirman que «los padres advierten que el niño actúa como si "estuviera activado por un motor" o como "si nunca se le acabaran las pilas"» (SAN SEBÁSTIÁN CABASÉS, J., SOUTULLO ESPERÓN, C. y FIGUEROA QUINTANA, A., «Trastorno...» cit., pág. 57). ${ }^{23}$ LÓPEZ SOLER, C., CASTRO SÁEZ, M., ISABEL BELCHÍ, A. y ROMERO MEDINA, A., «Descripción...» cit., págs. 14 y 15.

${ }^{24}$ GRATCH, L., El trastorno... cit., pág. 13.
} 
favorecen la ausencia de capacidad de contención. Buena prueba de ello es que el DSMIV recoge expresamente como criterios de diagnóstico el hecho de que los síntomas deben exteriorizarse en dos ambientes distintos -por ejemplo, escuela o trabajo, casa, etc-; o la existencia de pruebas claras de un deterioro significativo de la actividad social, académica o laboral.

Lo que sí resulta muy relevante es que el grado de afectación del trastorno al sujeto y sus relaciones con los demás podrá modularse, siguiendo a Gratch, de acuerdo a tres variables: grado de armonía psíquica, capacidades yoicas y el contexto familiar en el que crezca y se desenvuelva, permitiendo un mayor o menor despliegue de los inconvenientes derivados del trastorno; y, de ellos, el último es el que parece tener una incidencia más directa en la minoración de los efectos; esto es, una familia estructurada, ordenada, con reglas más consistentes (...) si bien no resulta curativa del trastorno sí incide en la intensidad de algunas manifestaciones somáticas ${ }^{25}$.

No obstante, a modo de simplificar y conocer las principales manifestaciones somáticas apreciables en el adulto, las cuales permitirán vincular la relación TDAH e imputabilidad, pueden referirse, siguiendo a Gratch y a San Sebastián Cabasés, Soutullo Esperón y Figueroa Quintana, las siguientes:

- Rendimiento por debajo de las capacidades a nivel laboral o profesional.

- Inestabilidad para conservar trabajos.

- Falta de capacidad para mantener la concentración por un largo período de tiempo.

- Falta de organización y caos.

- Escasa capacidad para cumplir con lo acordado.

\footnotetext{
${ }^{25}$ Ibídem, págs. 24 y 25.
} 
- Incapacidad para establecer una rutina y poder cumplirla.

- Olvidos, pérdidas y descuidos importantes.

- Depresión, daño crónico a la autoestima.

- Confusión, dificultades para pensar y expresarse con claridad.

- Frecuentes discusiones y peleas motivadas por la fuerte impulsividad presentada.

- Inestabilidad afectiva, lo cual puede conllevar múltiples separaciones.

- Tendencia a actuaciones impulsivas.

- Tendencia a interrumpir a otros, dificultades para escuchar y esperar su turno.

- Frecuentes choques automovilísticos a causa de la tendencia a estar distraídos y a una conducción impulsiva, frecuentes multas por exceso de velocidad y conducciones temerarias.

- Frecuente consumo de alcohol y abuso de sustancias ${ }^{26}$.

Aunque todas ellas son perfectamente identificativas del trastorno, aún siendo también características propias de otros recogidos en el DSM, debo traer especialmente a colación, por el objeto del estudio, las vinculadas a las constantes discusiones y peleas, actuaciones impulsivas, dificultad para escuchar y respetar turno, la conducción de vehículos a motor y el consumo de tóxicos ya que, debido a la impulsividad, motivada o no por la falta de atención, va a generar conductas ilícitas que el individuo, por la esencia del trastorno, no va a ser capaz de controlar en el momento de los hechos; esto es, un accidente de circulación motivado por su propia falta de atención -conducta muy habitual y característica del trastorno- puede derivar en una agresión por la propia impulsividad del sujeto ante el improperio del conductor que sufre el daño o incluso recibir la agresión por no prestar atención a los requerimientos del accidentado,

${ }^{26}$ GRATCH, L., El trastorno... cit., págs. 150 y 151; SAN SEBÁSTIÁN CABASÉS, J., SOUTULLO ESPERÓN, C. y FIGUEROA QUINTANA, A., «Trastorno...» cit., págs. 63 y ss. 
situaciones producidas, como se ha referido, de manera completamente involuntaria pero sin destrezas para actuar de otra forma debido al TDAH. A modo de ejemplo, tal y como puso de relieve originariamente Barkley, las personas que presentan TDAH tienen una mayor probabilidad de cometer conductas ilícitas vinculadas con la conducción ilegal -principalmente, conducción sin permiso de conducir-, así como una mayor incidencia en su suspensión o revocación una vez obtenida la licencia. Del mismo modo que, una vez conseguido, resultan más habituales y frecuentes las multas y citaciones judiciales por exceso de velocidad, llegando a incrementarse por cuatro la probabilidad de tener un accidente de tráfico cuando son ellos quienes conducen el vehículo ${ }^{27}$.

Por ello, a modo de resumen o conclusión, considero muy ilustrativa, desde la esfera de la imputabilidad, la identificación del trastorno llevada a cabo por San Sebastián Cabasés, Soutullo Esperón y Figueroa Quintana, quienes lo han vinculado a una alteración de la función ejecutiva; esto es, una modificación de las capacidades necesarias para atender a un estímulo, planificar y organizar una acción, reflexionar sobre las posibles consecuencias de las acciones e inhibir la primera respuesta automática cambiándola por otra más apropiada ${ }^{28}$. En consecuencia, analizadas y verificadas las variables mencionadas puede establecerse una mayor probabilidad de riesgo de comisión de ilícitos de las personas que presentan TDAH por las propias manifestaciones del trastorno en los términos descritos anteriormente piénsese, nuevamente, en el individuo que no posee la capacidad para contener la primera respuesta automática generada ante un hecho, en no pocos casos de naturaleza violenta o, cuanto menos, de rechazo externo, o la no verificación o evaluación de las consecuencias de un acto, actuando a través de impulsos-. Es más, de las distintas subcategorías, la que presentaría una mayor asociación con el hipotético desarrollo de comportamientos ilícitos, principalmente de naturaleza violenta, sería el subtipo impulsivo, debiendo especificar, siguiendo a Álvarez y Ollendick, que no sería tanto la consideración del trastorno en sí mismo como la repercusión de sus características del

27 BARKLEY, R.A., «Driving impairments in teens and adults with attention-deficit/hyperactivity disorder», Psychiatric Clinics of North America 27, 2004, pág. 235.

28 SAN SEBÁSTIÁN CABASÉS, J., SOUTULLO ESPERÓN, C. y FIGUEROA QUINTANA, A., «Trastorno....» cit., pág. 55. 
en otras esferas, pudiendo afirmar que el déficit en las habilidades ejecutivas concretas constituye la razón más evidente para predecir el inicio de trastorno de conducta o, lo que es lo mismo, quedaría vinculada parte de la naturaleza multidimensional del TDAH, pudiendo afirmar que sería la impulsividad la predoctora de posteriores conductas problemáticas, por encima de otros elementos como, por ejemplo, la hiperactividad ${ }^{29}$.

\section{Tipologías.}

A efectos meramente descriptivos, con el propósito de obtener un mayor conocimiento sobre los elementos identificativos del TDAH se recogen los criterios diagnósticos establecidos al efecto por el DSM-IV, advirtiéndose que deben cumplirse los cinco siguientes para diagnosticarlo:

1. Deben verificarse, al menos, seis síntomas persistentes por lo menos durante un período de seis meses con una intensidad incoherente conforme al nivel de desarrollo de la persona, debiendo distinguir entre los siguientes tipos:

A) Inatento. Su diagnóstico se produciría cuando aparezcan seis síntomas persistentes por lo menos durante un período de seis meses con una intensidad incoherente conforme al nivel de desarrollo de la persona:

- A menudo no presta atención suficiente a los detalles o incurre en errores por descuido en las tareas escolares, en el trabajo o en otras actividades.

\footnotetext{
${ }^{29}$ ÁLVAREZ, H.K. and OLLENDICK, T.H., «Individual and Psychosocial Risk Factors», in Cecilia A. Essau, Conduct and Oppositional Defiant Disorders. Epidemiology, Risk Factors, and Treatment, New Jersey, 2003, pág. 108 .
} 
- A menudo tiene dificultades para mantener la atención en tareas o en actividades lúdicas.

- A menudo parece no escuchar cuando se le habla directamente.

- A menudo no sigue instrucciones y no finaliza tareas escolares, encargos, u obligaciones en el centro de trabajo (no se debe a comportamiento negativista 0 a incapacidad para comprender instrucciones).

- A menudo tiene dificultades para organizar tareas y actividades.

- A menudo evita, le disgusta o es renuente en cuanto a dedicarse a tareas que requieren un esfuerzo mental sostenido (como trabajos escolares o domésticos).

- A menudo extravía objetos necesarios para tareas o actividades (por ejemplo, juguetes, ejercicios escolares, lápices, libros o herramientas).

- A menudo se distrae fácilmente por estímulos irrelevantes.

- A menudo es descuidado en las actividades diarias.

B) Hiperactivo-impulsivo. Incluiría dos subcategorías:

b1) Hiperactividad:

* A menudo mueve en exceso manos o pies, o se remueve en su asiento.

* A menudo abandona su asiento en la clase o en otras situaciones en que se espera que permanezca sentado.

* A menudo corre o salta excesivamente en situaciones en que es inapropiado hacerlo (en adolescentes o adultos puede limitarse a sentimientos subjetivos de inquietud).

* A menudo tiene dificultades para jugar o dedicarse tranquilamente a actividades de ocio. 
* A menudo "está en marcha" o suele actuar como si tuviera un motor.

* A menudo habla en exceso

b2) Impulsividad:

- A menudo precipita respuestas antes de haber sido completadas las preguntas.

- A menudo tiene dificultades para guardar tumo.

- A menudo interrumpe o se inmiscuye en las actividades de otros (p. ej. se entromete en conversaciones o juegos).

C) Combinado. Concurren las dos tipologías anteriores durante los últimos seis meses.

2. Los síntomas causaban alteraciones antes de los siete años.

3. Algunas alteraciones provocadas por los síntomas se presentan en dos o más ambientes.

4. Existen pruebas claras de un deterioro significativo de la actividad social, académica o laboral.

5. Los síntomas no aparecen exclusivamente en el transcurso de un trastorno generalizado del desarrollo, esquizofrenia u otro trastorno psicótico y no se explican mejor por la presencia de otro trastorno mental.

De acuerdo con las investigaciones de San Sebastián Cabasés, Soutullo Esperón y Figueroa Quintana, el TDAH combinado es el subtipo más frecuente, el que más se parece a las descripciones clásicas de este trastorno, asociándose a otros trastornos externalizantes o del comportamiento. Ahora bien, mientras aquél es más frecuente en niños que en niñas, el inatento es más usual en féminas que en varones, siendo más habitual que este subtipo se diagnostique a edades más avanzadas -primaria e incluso 
instituto- por no presentar problemas de comportamiento en casa o en clase, asociándose a trastornos internalizantes -principalmente, del humor o de ansiedad-. Por último, el hiperactivo-impulsivo es el menos frecuente de los tres existiendo incluso una línea de pensamiento que cuestiona hasta su existencia propia e independiente por tratarse de un estadio precoz del subtipo combinado en el que sólo la hiperactividad da problemas en ese momento y la disfunción por la inatención se manifiesta en cursos posteriores cuando al niño se le exijan tareas más complejas ${ }^{30}$.

\begin{tabular}{|c|c|c|}
\hline \multicolumn{3}{|c|}{ REPRESENTATIVIDAD DE LOS TIPOS DE TDAH POR SEXO3 } \\
\hline Tipo de TDAH & Niños & Niñas \\
\hline Combinado & $80 \%$ & $60 \%$ \\
\hline Inatento & $16 \%$ & $30 \%$ \\
\hline Hiperactivo-impulsivo & $3 \%$ & $7 \%$ \\
\hline
\end{tabular}

\section{INCIDENCIA DEL TDAH EN LA IMPUTABILIDAD}

\section{Fijación de la cuestión.}

Pese a que cada vez son más frecuentes las investigaciones realizadas sobre TDAH desde diversas ciencias, principalmente Psicología, Medicina, Sociología, no acontece lo mismo desde la esfera del Derecho, donde el citado trastorno constituye hoy día uno de los grandes desconocidos pese a que cada vez aparecen con mayor intensidad

\footnotetext{
${ }^{30}$ SAN SEBÁSTIÁN CABASÉS, J., SOUTULLO ESPERÓN, C. y FIGUEROA QUINTANA, A., «Trastorno...» cit., págs. 60 y 61.

${ }^{31}$ Ibídem.
} 
casos en la planta judicial española en los que no sólo se alega la presencia del TDAH en el sujeto activo del delito, sino que se acompaña de informes periciales que acreditan la presencia del citado trastorno desde incluso la infancia/adolescencia, pudiendo, no sólo motivar la conducta criminal, tal y como se ha referido en el epígrafe anterior, sino explicar el por qué del comportamiento ilícito desde una perspectiva lógica, incidiendo sobre la imputabilidad del individuo y, llegado el caso, motivar una exclusión o atenuación de la responsabilidad penal. Sin embargo, la respuesta de los Tribunales a semejante relación es, como se detallará posteriormente, prácticamente nula, prestando una escasa atención a la presencia del trastorno y su eficacia en la imputabilidad o, caso de hacerlo, utilizando razonamientos o comparativas a todas luces incorrectas, cuestión más que llamativa en determinados supuestos en los que es el propio abogado defensor quien desconoce la naturaleza del trastorno procediendo a construir el hilo argumental de la defensa sobre parámetros erróneos. Así, por ejemplo, es relativamente habitual equiparar el trastorno por déficit de atención e hiperactividad como sinónimo de trastorno de la personalidad ${ }^{32}$.

En consecuencia con lo anterior, el punto de partida para determinar o verificar la afectación de la imputabilidad del adulto que presenta TDAH y desarrolla un comportamiento delictivo radica en el propio concepto de imputabilidad y los efectos propios derivados del citado trastorno, lo cual va a devenir en una cuestión fundamental de cara al futuro del trastorno: la imposición de una pena o medida de seguridad.

Mir Puig ha sido muy claro al afirmar que sólo tiene sentido prohibir los hechos antijurídicos a quienes pueden conocer su antijuridicidad, por lo que la incapacidad personal de evitar el hecho procedente de una causa de inimputabilidad elimina la capacidad de evitación; esto es, la infracción de una norma permite imputar la

\footnotetext{
32 A modo de ejemplo, véase el Auto de la Audiencia Provincial de Madrid 773/2012, de 7 de julio [JUR 2012\289461].
} 
antijuridicidad penal a su autor pero eso no basta para considerar adecuada la imposición de una pena ${ }^{33}$.

En este sentido, pese a tratarse de una cuestión que afecta de lleno a la culpabilidad, entendida como el conjunto de presupuestos que fundamentan frente al sujeto la reprochabilidad personal de su conducta típica y antijurídica, la imputabilidad constituye el elemento primigéneo de la culpabilidad, pareciendo lo más adecuado reducir su análisis directamente hacia la esfera de la imputabilidad, ya que es ahí donde surgen las cuestiones más conflictivas y que ahora interesan.

Así pues, en primer lugar, para una correcta y adecuada ubicación de los postulados teóricos a tratar, resulta indispensable un acercamiento, siquiera somero, al clásico debate sobre la libertad de determinación del individuo y la motivabilidad, dos realidades que, en cierto sentido, no tienen por qué aparecer tan alejadas ${ }^{34}$ ya que, como afirmó Suárez-Mira Rodríguez, quien es motivable por la norma es libre de determinarse conforme a ella y viceversa ${ }^{35}$.

Sin embargo, contrariamente a la última afirmación realizada, las posiciones doctrinales mayoritarias las consideran extremos opuestos ya que mientras la libertad de voluntad tendría su origen en el libre albedrío y, en particular, en la libertad del hombre para decidir en uno u otro sentido cómo actuar, jugando un papel nuclear las capacidades de entender y querer de la persona, y el juicio de reproche que se haría al autor por haberse comportado de modo contrario al Derecho, habiendo podido hacerlo

\footnotetext{
${ }^{33}$ MIR PUIG, S., Derecho Penal. Parte General, Barcelona, 2011, págs. 541-543.

${ }^{34}$ Véase, más ampliamente, CASTELLÓ NICÁS, N., La imputabilidad penal del drogodependiente, Granada, 1997, págs. 66 y ss; NÁQUIRA RIVEROS, J., «Imputabilidad, conciencia de lo injusto y contexto situacional normal: de su objeto, contenido y relación», en Cuadernos de Política Criminal, $n^{o}$ 55, 1995, pág. 141; SUÁREZ-MIRA RODRÍGUEZ, C., La imputabilidad del consumidor de drogas, Valencia, 2000, págs. 73-75.

${ }^{35}$ SUÁREZ-MIRA RODRÍGUEZ, C., La imputabilidad...cit., pág. 74.
} 
de acuerdo con él ${ }^{36}$; otro sector doctrinal entiende insostenible la citada tesis ${ }^{37}$ debido a que se basa en algo indemostrable, como es esa voluntad o libre albedrío y la reducción de todas las facultades humanas a los planos intelectivo y volitivo, los cuales, además, no son los únicos existentes, ya que se encuentran condicionados por otra serie de factores, que también deben ser relevantes en la determinación de la capacidad de culpabilidad, como pudieran ser los psíquicos y socioculturales, no pareciendo, en opinión de Muñoz Conde y García Arán, lo más idóneo, sino un proceso más amplio fruto de la interacción social con la que conviven diariamente los ciudadanos, en virtud de las cuales desarrolla una serie de facultades que le permiten conocer las normas que rigen la convivencia en el grupo al que pertenece y regir sus actos conforme a ellas, creándose un complejo proceso de interacción y comunicación que se corresponde con lo que la Psicología moderna denomina "motivación", lo cual no es otra cosa que la capacidad para motivarse a nivel individual por los mandatos normativos y así, quien no haya alcanzado esa capacidad por falta de madurez, defectos psíquicos de cualquier origen o por trastornos transitorios no podrá ser considerado culpable ${ }^{38}$.

Sea como fuere, ambas posiciones llegan a un postulado de encuentro común y eso es lo relevante a los efectos del presente artículo: el que carece del punto nuclear de ambas construcciones; esto es, de capacidad de entender y querer, para el primer caso, y de motivación, en el segundo, no puede tener capacidad de culpabilidad en el sentido de ser considerado como imputable. Así pues, según la opción doctrinal mantenida, imputable será la persona que presente las facultades psíquicas mínimas requeridas para, o bien valorar y comprender la ilicitud del hecho y actuar en los términos requeridos por el ordenamiento jurídico ${ }^{39}$, o para poder ser motivado en sus actos por los mandatos normativos ${ }^{40}$.

\footnotetext{
${ }^{36}$ Véase, más ampliamente, por todos, CASTELLÓ NICÁS, N., «Art. 20.1», en Cobo del Rosal (Dir.), Comentarios al Código Penal, Tomo II, Madrid, 1999, págs. 102-107.

${ }^{37}$ Véase, a modo de ejemplo, QUINTERO OLIVARES, G., Locos y culpables, Navarra, 1999, págs. 106-110.

${ }^{38}$ MUÑOZ CONDE, F. y GARCÍA ARÁN, M., Derecho Penal. Parte General, Valencia, 2010, pág. 362.

${ }^{39}$ COBO DEL ROSAL, M. y VIVES ANTÓN, T.S. Derecho Penal. Parte General, Valencia, 1999, pág. 575.

${ }^{40}$ Véase, MUÑOZ CONDE, F. y GARCÍA ARÁN, M., Derecho...cit., pág. 361.
} 
En ese sentido, Martínez Garay diferenció la imputabilidad de la inimputabilidad por la exigibilidad/inexigibilidad de la conducta motivada por la afectación de los procesos psíquicos - de la decisión de la voluntad-. En particular identificó a la primera como exigibilidad de conducta adecuada a derecho por no encontrarse alterada de manera relevante la estructura de los procesos psíquicos de la decisión de voluntad que dio lugar a la realización del delito; mientras la segunda sería justamente lo contrario; esto es, la inexigibilidad de conducta adecuada a derecho, por alteración patológica suficientemente relevante, desde el punto de vista del principio de igualdad, de la estructura de los procesos psíquicos cognitivos y/o afectivos de la decisión de voluntad que dio lugar a la conducta delictiva ${ }^{41}$.

No obstante, de acuerdo con todo lo anterior, y no restando relevancia a ninguna de las aportaciones enunciadas, el concepto de imputabilidad defendido se encuentra más próximo a los postulados de Cobo del Rosal y Vives Antón, quienes la vincularon con el conjunto de requisitos psicobiológicos, exigidos por la legislación penal vigente, que expresan que la persona tiene capacidad de valorar y comprender la ilicitud del hecho realizado y actuar en los términos requeridos por el ordenamiento jurídico ${ }^{42}$; constituyendo esta opción, a juicio de Urruela Mora, la descripción mayoritaria seguida por la doctrina; esto es, su identificación con la capacidad de comprender la ilicitud del hecho y actuar conforme a esa comprensión ${ }^{43}$.

En consecuencia, de las citadas descripciones se derivan dos cuestiones nucleares para verificar la imputabilidad del sujeto:

\footnotetext{
${ }^{41}$ MARTÍNEZ GARAY, L., La imputabilidad penal, Valencia, 2005, pág. 365.

${ }^{42}$ COBO DEL ROSAL, M. y VIVES ANTÓN, T.S. Derecho... cit., pág. 576.

${ }^{43}$ Véase, a modo de ejemplo, URRUELA MORA, A., Imputabilidad penal y anomalía o alteración psíquica, Granada, 2004, pág. 156.
} 
i) La imputabilidad se construye sobre dos esferas de la persona: la capacidad para comprender la ilicitud del hecho -elemento cognitivo- y la capacidad de actuar conforme a esa comprensión -elemento volitivo-.

ii) Los Códigos Penales modernos han optado por no definir expresamente el concepto de imputabilidad sino recurrir a un criterio negativo para su identificación; esto es, delimitar las causas concretas que dan origen a situaciones de inimputabilidad o semi-imputabilidad, debiendo entender, en consecuencia, que todo lo que no aparece recogido bajo las citadas descripciones validaría la plena imputabilidad del sujeto. En el caso del Texto punitivo español, semejantes descripciones pueden encontrarse en el artículo 20, apartados 1 -anomalía o alteración psíquica-, 2 -intoxicación plena por consumo de bebidas alcohólicas, drogas tóxicas, estupefacientes, sustancias psicotrópicas u otras que produzcan efectos análogos o hallarse bajo la influencia de un síndrome de abstinencia-, y 3 -presentar alteraciones en la percepción desde el nacimiento o la infancia-.

Así pues, a modo de resumen, como subrayó Urruela Mora, la imputabilidad es la capacidad de comprender la ilicitud del hecho y actuar conforme a dicha comprensión, por lo que exige para su concurrencia una serie de requisitos biopsíquicos para el autor, que en el caso de concurrir lo convierten en receptor adecuado de la prescripción normativa contenida en la ley penal y en sujeto capaz de autodeterminación con arreglo a la misma. El Código Penal español ha consagrado una fórmula mixta (psiquiátrico-psicológica) en materia de imputabilidad, por lo que su exclusión exige, por un lado, el requisito psiquiátrico (psíquico) de la efectiva concurrencia de un trastorno mental permanente o transitorio, estado de intoxicación o alteración sensorial, $\mathrm{y}$, por otro, el factor psicológico, consistente en la incidencia que dichas circunstancias han de ostentar sobre el actuar del sujeto ${ }^{44}$.

\footnotetext{
${ }^{44}$ Ibídem, pág. 158.
} 
La pregunta a formular es consecuentemente clara: ¿presenta el TDAH efectos intrínsecos que afecten a las facultades cognoscitivas y volitivas del individuo que lo padece? La respuesta, como se apreciará en el epígrafe siguiente, es compleja. No obstante, el punto de partida es claro y evidente: se trata de un trastorno y no de una enfermedad mental, lo que conlleva, siguiendo a Martínez Garay sobre los postulados del CIE-10 y el DSM-IV, la presencia de un comportamiento o grupo de síntomas identificables en la práctica clínica, que en la mayoría de los casos se acompañan de malestar o interfieren en la actividad del individuo ${ }^{45}$.

Ahora bien, sus efectos al respecto son muy dispares y así, en primer lugar, habría que verificar exclusivamente si el autor del hecho delictivo era capaz de comprender la ilicitud de su actuación en el momento de comisión del delito; esto es, en palabras de Urruela Mora, se trata de un criterio fundado en la potencialidad intelectiva del sujeto con base en su situación bio-psicológica; esto es, la facultad de entender el carácter prohibido de la conducta concretamente realizada ${ }^{46}$.

En mi opinión, en el caso del trastorno por déficit de atención e hiperactividad, de acuerdo con todo lo expuesto en el epígrafe primero, semejante afectación no acontece pues el sujeto es en todo momento plenamente consciente de la ilicitud del hecho cometido. Es más, el citado trastorno no conlleva deterioro cognitivo alguno sino modificaciones o alteraciones funcionales o de la capacidad ejecutiva, debiendo negar, de manera rotunda, afectación alguna en este sentido. Semejante tesis ha sido defendida igualmente por la Jurisprudencia y así, por ejemplo, como se explicitará en el epígrafe siguiente, la Sentencia del Tribunal Supremo 802/2009, de 7 de julio [RJ 2009\6711], ha señalado que no existen datos empíricos que corroboren el citado postulado y, en el caso enjuiciado -TDAH tipo combinado-, si bien no puede generalizarse al respecto, el acusado no tiene limitada su capacidad de comprensión de la ilicitud de la acción ya que nada más ver a los agentes se desprende de las pastillas de droga que portaba; o el Auto

\footnotetext{
${ }^{45}$ MARTÍNEZ GARAY, L., La imputabilidad... cit. págs. 303 y 304.

${ }^{46}$ URRUELA MORA, A., Imputabilidad... cit., pág. 165.
} 
del Tribunal Supremo 428/2010, de 11 de marzo [JUR 2010\100368], al manifestar que las capacidades intelectivas y volitivas se encuentran dentro de la normalidad, pese a los distintos trastornos presentados por el acusado, entre ellos TDAH ${ }^{47}$.

Por el contrario, donde creo que existen mayores dudas y el debate se torna más prolijo, constituyendo el elemento nuclear de la cuestión, es en la afectación de la facultad volitiva ya que, a mi juicio, representa la única opción posible para plantear una modificación en la imputabilidad del autor del hecho ilícito en tanto, como ya se ha referido, la capacidad cognitiva aparece inalterada debiendo reconducir todos los postulados aplicativos hacia la repercusión que el TDAH presenta en la capacidad ejecutiva del individuo en el sentido de si es capaz de orientar semejante conocimiento hacia su voluntad.

La respuesta a esta pregunta, clave para determinar la posible afectación del nivel de imputabilidad de la persona que padece TDAH, no resulta, para nada sencilla, como podrá observarse en el epígrafe siguiente, pudiendo residir la clave de la respuesta, no en hacer una valoración conjunta del trastorno, independientemente del hecho de verificar la imputabilidad siempre a nivel particular; esto es, casos por caso, sino según la incidencia presentada en la voluntad de la persona en el instante de comisión del delito, resultando indispensable diferenciar los subtipos de TDAH inatento, hiperactivo-impulsivo y combinado- ya que las particularidades de cada uno son muy dispares en la temática que ahora me ocupa. Así, por ejemplo, en mi opinión, de acuerdo con las características identificativas de cada uno, la posibilidad de apreciar una afectación en la imputabilidad de la persona es mayor si el subtipo es exclusivamente impulsivo frente al inatento o, donde más dificultades aprecio, en el hiperactivo en sentido estricto. La explicación para establecer una diferenciación de niveles viene puesta de manifiesto por las características de cada uno. Así, por ejemplo,

\footnotetext{
${ }^{47}$ Las Audiencias Provinciales, como se detallará en el epígrafe siguiente, mantienen la citada tesis, siendo el caso más paradigmático el de la Sentencia de la Audiencia Provincial de Alicante 675/2005, de 29 de septiembre [JUR 2008\286751], único en el que se aplica una eximente incompleta por la presencia del TDAH, con otros trastornos, fundando la modificación de la imputabilidad del sujeto en una afectación de su capacidad volitiva, presentando inalterada la cognitiva.
} 
el de corte impulsivo presenta una clara imposibilidad de controlar sus impulsos, lo que lleva aparejado que actúe para dar respuesta a los mismos, pudiendo afirmarse que, aunque no es del todo correcto pero creo que ejemplifica bastante lo que quiero poner de manifiesto, lo hace por impulso natural, porque no tiene otra forma de responder al estímulo, lo que lleva a una desinhibición y ausencia de control, aún conociendo la ilicitud de la acción, por el trastorno neuroconductual presentado; de otro lado, el inatento se caracteriza por presentar una falta de atención con determinados estímulos lo que implica una desatención en las actividades que puede estar desarrollando generándose la conducta ilícita precisamente por una falta de atención a actividades principales por estímulos secundarios que "lo distraen de lo que debería estar haciendo", pudiendo equipararse a una hipoprosexia en el sentido de que genera una disminución de la capacidad de atención del sujeto que es lo que va a originar la producción del ilícito; y, por último, el hiperactivo en sentido estricto, cuya vinculación directa con el comportamiento criminal es más compleja por su naturaleza, si bien puede ser el causante o generador del delito producido, principalmente contra la persona o la salud, debido al constante movimiento, no poder realizar actividades de ocio de manera tranquila, desarrollo de comportamientos físicos en situaciones inapropiadas $(\ldots)^{48}$.

\section{Respuestas dadas por la Jurisprudencia.}

Frente a la doctrina jurídico-penal, que no ha entrado a valorar los posibles efectos en torno a la imputabilidad derivados de la comisión de un delito por una persona que presente TDAH, debiendo aplicar simplemente los postulados genéricos al respecto, lo cual no aporta absolutamente nada a la especificidad del trastorno, por el contrario, en la Jurisprudencia, sí se encuentran referencias al respecto derivadas del análisis de casos particulares si bien, en la mayoría de supuestos, con escaso nivel de

\footnotetext{
${ }^{48}$ No he referido nada del tipo combinado ya que, dependerá de las tipologías anteriores concurrentes para poder establecer la correspondiente afectación.
} 
comprensión del trastorno y sus especificidades, lo que denota un nuevo y enorme desconocimiento del trastorno. No obstante, cuanto menos, empiezan a existir líneas argumentales, embrionarias en los casos más acertados y confusos en la mayoría por no conocer el significado e implicaciones del TDAH, lo cual tampoco debe achacarse a los jueces y magistrados, como resaltaré posteriormente.

Así pues, se ha realizado una revisión jurisprudencial del tratamiento otorgado por los Tribunales de Justicia españoles a los casos en los que el autor de los hechos imputados presentaba trastorno por déficit de atención e hiperactividad (TDAH), pudiendo afirmarse, sin ningún riesgo de equivocación, que el citado trastorno constituye un gran desconocido en la planta jurisdiccional española ya que son frecuentes los razonamientos basados en equiparaciones o similitudes con otros trastornos, cuando no es así, no observándose la apreciación de ningún tipo de eximente, ya sea completa o incompleta -salvo un caso particular-, ni atenuante concreta alguna por padecerlo, utilizándose la vía de la atenuante analógica para abrir un resquicio atenuatorio sobre la premisa de la alteración psíquica, si bien las citadas manifestaciones son escasas. Es más, en los supuestos en que se aprecia alguna circunstancia modificativa de la responsabilidad penal del autor, no suele ser por el propio TDAH sino por su confluencia con otros trastornos o adicciones que son los que fundamentan semejante atenuación punitiva.

De conformidad con lo anterior, el esquema de trabajo presentado se ha dividido en dos grandes bloques para obtener una mejor aproximación a las manifestaciones jurisprudenciales que inciden en la valoración del TDAH en la esfera de la imputabilidad del autor del delito, distinguiendo, por un lado, la jurisprudencia del Tribunal Supremo; y, por otro, los razonamientos seguidos por las distintas Audiencias Provinciales. 


\subsection{Tribunal Supremo.}

Se han revisado las dieciocho Sentencias emanadas del Alto Tribunal, de las cuales dos han sido eliminadas por contener referencias incorrectas a los parámetros de búsqueda -“déficit de atención" e "hiperactividad"-, conformando una muestra de dieciséis, en las que el imputado presenta un trastorno por déficit de atención e hiperactividad. De ellas, la mayoría simplemente lo describe como un trastorno padecido por el sujeto, junto a otros vinculados, principalmente, a la personalidad o adicciones, sin entrar a profundizar en él, mayoritariamente porque la propia parte defensora no lo ha invocado como posible elemento atenuatorio de la responsabilidad penal del sujeto ${ }^{49}$.

Sin embargo, tomando en consideración aquellas en las que sí se ha aducido y el Tribunal Supremo ha entrado a analizar su incidencia, se traen a colación las siguientes manifestaciones, las cuales considero más representativas de las hipótesis descritas, recurriendo a un criterio cronológico en su enumeración:

A) El Auto del Tribunal Supremo 428/2010, de 11 de marzo [JUR 2010\100368], viene a reafirmar el razonamiento seguido por la Audiencia Provincial de Valencia quien, en su Sentencia 421/2009, de 29 de junio [JUR 20091376359], aplicó una atenuante analógica por anomalía o alteración psíquica del acusado, quien padecía un trastorno de inestabilidad emocional de la personalidad de tipo impulsivo o trastorno límite de la personalidad, de intensidad moderada, que, sin embargo, no afectaron a la inteligencia y voluntad del acusado. Sin embargo, de manera conjunta con lo anterior, y reconocido por todas las partes implicadas, el imputado presentaba igualmente un trastorno por déficit de atención, trastorno del control de los impulsos, trastorno de ansiedad de alta intensidad y rasgos anómalos de la personalidad, de lo que se desprende una evidente dificultad para controlar sus impulsos, estando en tratamiento

\footnotetext{
${ }^{49}$ En otras simplemente se describe la presencia del TDAH en uno de los imputados y nada más -vid., a modo de ejemplo, la Sentencia del Tribunal Supremo 810/2010, de 30 de septiembre [RJ 201017648]-.
} 
desde 2000 con altas dosis de medicación. Y, en atención a esto último, corrobora la sentencia conforme a lo manifestado por la Audiencia, no presenta las facultades intelectivas y volitivas significativamente alteradas sino prácticamente dentro de la normalidad, debiendo verificar la aplicación de la atenuante analógica debido al trastorno presentado y el tratamiento que venía recibiendo desde el año 2000, lo que evidencia una necesidad de intervención para controlar sus impulsos, por mínima que sea $^{50}$.

B) El Auto del Tribunal Supremo 274/2010, de 11 de [JUR 2010\82466], incide en lo que desgraciadamente viene siendo una práctica habitual en los supuestos en los que se alega la presencia de TDAH en el imputado: una mala praxis por parte de los sujetos intervinientes. En este sentido, la responsabilidad parece recaer en el informe pericial emitido al respecto, donde se pone de manifiesto que al procesado se le diagnosticó a los ocho años de edad un trastorno de hiperactividad con déficit de atención, que fue tratado farmacológicamente durante un año y los tres siguientes con psicoterapia. Posteriormente se inició en el consumo de cannabis, presentando fracaso escolar y alteraciones conductuales. El 30 de mayo de 2006 se integró en el Programa de Adolescentes y Familias del Centro español de Solidaridad-Proyecto Hombre, en cuyo desarrollo se consideró que no era precisa medicación y recibió terapia de apoyo individual. Sin embargo, semejante informe no fue tenido en consideración por el Tribunal al no aportar las copias de las pruebas diagnósticas e informes que explícita haber analizado, no constando semejante trastorno en posteriores seguimientos médicos ni en los demás informes periciales emitidos al respecto.

No obstante, conforme a lo anterior, el Tribunal Supremo concluye diciendo que la única posibilidad de asociar relevancia al trastorno padecido sería a la toxicomanía presentada y no por el trastorno en sí.

\footnotetext{
${ }^{50}$ La referencia al trastorno versa sobre el trastorno del control de impulsos intenso presentado, el cual guarda una vinculación evidente con el TDAH en su subcategoría de impulsivo y, llegado el caso, combinado.
} 
C) En la Sentencia del Tribunal Supremo 802/2009, de 7 de julio [RJ 200916711], la parte recurrente intenta el reconocimiento del TDAH por aplicación de la atenuante analógica del artículo 21.6 del Código Penal en relación con el artículo 20.2 ${ }^{\text {a }}$ del Texto Punitivo, donde se motiva pericialmente que el acusado presenta TDAH tipo combinado, si bien la Sala entendió que no existen datos objetivos empíricos contrastados que fundamenten la acreditación de una anomalía psíquica que permita hablar de reducción de la imputabilidad, destacando que, pese a ser cierto lo anterior, no se ha acreditado que «el acusado tuviera limitada su capacidad de comprensión de la ilicitud de la acción (de hecho, se desprendió de la bolsa con las pastillas nada más ver a los agentes) ni tampoco se ha probado que no pudiera ajustar su conducta a las exigencias de esa comprensión», no existiendo una base psicopatológica suficiente para acreditar la justificación en la aplicación de una atenuación penológica, lo cual, en consecuencia, se rechaza.

De acuerdo con lo anterior, para que el Alto Tribunal estime una atenuante es preciso acreditar la realidad del hecho que la justifique y su concurrencia en el momento de la comisión de la conducta enjuiciada, lo cual no queda probado en el informe pericial presentado ni tampoco cabe derivarlo del comportamiento del autor el día de los hechos $^{51}$, tal y como lo evidencia el desprendimiento de las bolsas al ver a los agentes, lo cual prueba justamente lo contrario, que era plenamente consciente de lo que hacía, ni que, conociendo la ilicitud, no pudiera atemperar su conducta a tal comportamiento.

D) El Auto del Tribunal Supremo 260/2009, de 5 de febrero [JUR 2009187232], rechaza la aplicación de cualquier atenuante o eximente pese a constatar la apreciación expresa de un TDAH, rechazándose en el informe forense una patología psiquiátrica y constatándose solamente una personalidad impulsiva, añadiendo el Tribunal de instancia que la misma es insuficiente para apreciar una atenuante. Por tanto, para el

\footnotetext{
${ }^{51}$ Siguiendo ese mismo razonamiento, véase el Auto del Tribunal Supremo 500/2007, de 15 de marzo [JUR 2007\98150], si bien se asocia únicamente al consumo de tóxicos, dejando de lado el TDAH presentado por el imputado.
} 
Alto Tribunal, la valoración efectuada por la Audiencia Provincial se muestra razonable, lógica y de acuerdo con las máximas de la experiencia.

Así pues, de acuerdo con las manifestaciones expuestas, el tratamiento otorgado por el Tribunal Supremo al TDAH, a efectos de imputabilidad, se vincula a la plena imputabilidad de la persona, pudiendo aspirar, como mucho, a la presencia de la circunstancia atenuante analógica del actual artículo $21.7^{\mathrm{a}}$ en relación con la alteración psíquica del parágrafo $20.1^{\circ}$ del Código Penal, no bastando la mera acreditación de la presencia del TDAH en la persona sino verificando sus efectos durante la comisión del hecho delictivo como consecuencia de la imposibilidad de controlar los impulsos siempre y cuando fuere necesario la adopción de medidas médico-farmacológicas para controlar la impulsividad.

\subsection{Audiencias Provinciales.}

Existen un total de sesenta y seis sentencias en las que el trastorno por déficit de atención e hiperactividad aparece enunciado en alguna de las partes del texto, si bien mayoritariamente vuelve a ser, de nuevo, de manera meramente descriptiva, como trastorno que se presenta conjuntamente a otros o adicciones y del que no se detalla nada en particular.

No obstante, existen evidencias jurisprudenciales que parecen aproximarse a los parámetros de actuación necesarios para verificar la aplicación del TDAH como circunstancia modificativa de la responsabilidad penal o, cuanto menos, plantearlo a los Tribunales para proceder a su valoración en el caso concreto, si bien, en la mayoría de supuestos, pasa desapercibido por no poder probar su efectiva vinculación a los hechos ilícitos cometidos. Así, a modo de ejemplo, las Sentencias de la Audiencia Provincial de Vizcaya 212/2012, de 16 de marzo [JUR 2012\188749], reconoce el diagnóstico emitido 
de que el imputado presentaba TDAH si bien excluye su valoración en la imputabilidad en tanto, como consta pericialmente, «el estado psicofísico presentado el día de los hechos no se debe a los síntomas de hiperactividad que padece»; mientras la 11/2010, de 26 de enero [JUR 2010\149022], parte del informe pericial en el que se reconoce un TDAH sin tratamiento, lo cual hace que el sujeto, para intentar controlar las actitudes desafiantes y oposicionistas, actúe de forma irreflexiva, sin importarle los resultados más allá de calmar su ansiedad de forma inmediata, ante lo cual, a efectos de imputabilidad, el elemento intelectivo, constituido por la capacidad de conocer el carácter ilícito de las conductas, no se encontraba modificado y que el elemento volitivo, entendido como la capacidad de actuar conforme al conocimiento de la ilicitud de las conductas, tampoco se encontraba modificado, concluyendo que no existen modificadores de su imputabilidad

Sea como fuere, el tratamiento jurisprudencial otorgado al TDAH por las distintas Audiencias Provinciales, en relación a su afectación a la imputabilidad de la persona, debiendo tener presente que en la mayoría de supuestos no entra a detallarse nada al respecto, se configura sobre los siguientes postulados:

A) Apreciación de una eximente incompleta. La Sentencia de la Audiencia Provincial de Alicante 675/2005, de 29 de septiembre [JUR 2008\286751], estima parcialmente el recurso interpuesto considerando la presencia del TDAH no como una circunstancia atenuante analógica sino como una eximente incompleta, en la única manifestación jurisprudencial existente al respecto, si bien, si se profundiza en el contenido de los razonamientos jurídicos, puede observarse más de una inexactitud.

Los hechos en cuestión parten de un claro trastorno por déficit de atención e hiperactividad junto con un trastorno antisocial de la personalidad y capacidad intelectual límite ${ }^{52}$ del imputado desde los dos años de edad, lo cual es corroborado por

\footnotetext{
${ }^{52} \mathrm{Si}$ bien el contenido de la sentencia se refiere en exclusividad al primero.
} 
seis informes médicos. Ahora bien, el médico forense, por el contrario, manifiesta que en el momento de la exploración no existen déficits en la capacidad intelectiva y volitiva del sujeto en relación a los hechos imputados, si bien, dada la naturaleza del trastorno y su presencia desde la infancia, no es descartable la afectación parcial de su capacidad volitiva con respecto al hecho imputado. Semejante declaración, a juicio de la Audiencia Provincial, adquiere su máxima significación en el sentido de que la capacidad volitiva se encuentra seriamente mermada, afectando no sólo a su comportamiento conductual, sino también a la comprensión de la posible gravedad del acto incendiario que se le imputa. Por todo ello, la Audiencia entiende que el estado de anomalía psíquica padecido por el acusado presenta la trascendencia suficiente para dar lugar a la apreciación no de una atenuante analógica del art. 21.6 -actual 21.7ª -, sino de una eximente incompleta del art. 21.1 ${ }^{\mathrm{a}}$ en relación con el art. $20.3^{\circ}$ del Código Penal.

Como puede comprobarse, no queda muy claro el razonamiento final seguido por la Audiencia Provincial ya que, pese a hablar de anomalía psíquica, menciona expresamente el apartado $3^{\circ}$, el cual incluye las alteraciones de la percepción. En mi opinión, semejante razonamiento pudiera validarse desde el prisma de la alteración psíquica pero no de la percepción. Sin embargo, pese a tratarse de una resolución pionera, no ha vuelto a tener incidencia en ningún supuesto de TDAH ni de ésta ni de otra Audiencia Provincial por lo que el hilo argumental seguido no parece consolidado sino más bien todo lo contrario.

B) Atenuación de la responsabilidad penal. La opción más valorada por las Audiencias, dentro de la escasez de manifestaciones existentes al respecto, es la ya citada aplicación de la atenuante analógica en relación con el $21.1^{\circ}$ y el $20.1^{\circ}$ derivado de la alteración psíquica. El problema es que en la mayor parte de ellas no consta que sea expresamente por el TDAH sino por la suma de varios trastornos ${ }^{53}$. Sin embargo, este hecho no acontece, en lo que podría calificarse como manifestación paradigmática

\footnotetext{
${ }^{53}$ En este sentido, véase, a modo de ejemplo, por todas, las Sentencias de las Audiencias Provinciales de Madrid 286/2013, de 13 de junio [JUR 2013/261463]; y Vizcaya 18/2012, de 2 de marzo [JUR 2012\188903].
} 
al respecto $^{54}$, en la Sentencia de la Audiencia Provincial de Barcelona 225/2005, de 6 de abril [ARP 20051233], donde, partiendo de la premisa de que el acusado padece un trastorno de déficit de atención con hiperactividad desde la infancia, traduciéndose ello en una notable dificultad en el control de sus impulsos, con un importante grado de intolerancia a la frustración y reacciones con heteroagresividad, que en sí pueden suponer una alteración de su capacidad volitiva en modo alguno le impiden conocer la trascendencia de sus actos, procede a aplicar la atenuante analógica en relación con los artículo $21.1^{\circ}$ y $20.1^{\text {a }}$ del Código Penal, si bien conviene advertir que el razonamiento seguido se basa en una equiparación entre el TDAH y los trastornos de la personalidad, para concluir que el fundamento de la atenuación radica en la reiterada «doctrina de esta sala que, en estos casos de trastorno de la personalidad, permite aplicar esta circunstancia del art. 21.6 por encontrarse afectada, no la capacidad de conocer ("la comprensión de la ilicitud del acto", en expresión del art. 20.1 y 3), sino la de controlar sus impulsos ("actuar conforme a esa comprensión", dicen tales apartados 1 y 3 del art. 20)» y en consecuencia dicha afectación del control de los impulsos a que se refieren en sus informes los médicos forenses y que incide en una limitación de sus facultades volitivas, no afecta para nada a su capacidad cognoscitiva, siendo plenamente consciente de los actos que está realizando y del reproche penal que los mismos merecen, lo que exige apreciar una disminución leve de su imputabilidad que sólo alcanza a una atenuante analógica pero en ningún caso puede determinar la apreciación de una circunstancia eximente completa o incompleta como pretende la defensa».

No obstante, pese a ser la opción más lógica, otros Tribunales han preferido seguir otra valoración, entiendo que errónea, para proceder a atenuar la pena. En este sentido, la Sentencia de la Audiencia Provincial de Navarra 138/2010, de 15 de septiembre [JUR 210\110396], reconoce que en el momento de los hechos el acusado era consumidor habitual de sustancias estupefacientes, en concreto cocaína y sufría un

\footnotetext{
${ }^{54}$ Más recientemente, pudiera ser del mismo modo, la Sentencia de la Audiencia Provincial de Madrid, 274/2013, de 31 de mayo [JUR 2013/207350], donde se le aplica al imputado la atenuante analógica por padecer un «trastorno psiquiátrico de hiperactividad» del que se encuentra en tratamiento y ha producido una merma en su capacidad cognitiva y volitiva, sin llegar a anularla. El problema es que se desconoce si el Tribunal se está refiriendo a un supuesto de TDAH ni especifica los motivos que llevan a considerar afectadas las citadas capacidades ni en qué medida.
} 
trastorno por déficit de atención con hiperactividad, que afectaba de modo leve a sus facultades volitivas, por falta de control de la impulsividad, lo que motivó la aplicación de sendas atenuantes: i) la analógica de trastorno mental del artículo $21.6^{\circ}$-en la actualidad $21.7^{\circ}$ - en relación con el $20.1^{\circ}$; y ii) la circunstancia atenuante analógica de toxicomanía con el $20.2^{\circ}$.

Por último, considero muy adecuado traer aquí a colación la Sentencia de la Audiencia Provincial de Madrid 322/2009, de 10 de julio [JUR 20091340910], por constituir uno de los casos más paradigmáticos en el tratamiento jurisprudencial del TDAH, en lo relativo a la afectación de la imputabilidad de la persona, en tanto la defensa del procesado intentó que el citado trastorno diera origen a la aplicación de una eximente completa, incompleta o atenuación por arrebato, obcecación o estado pasional. Sin embargo, las expectativas depositadas en los razonamientos jurídicos del Tribunal pierden todo su peso en el instante que se equipara el TDAH a un trastorno de la personalidad, por lo que las motivaciones recogidas pierden todo carácter científico sobre la base de las aportaciones jurisprudenciales que vienen a negar semejante postulado. No obstante, dicho lo anterior, el TDAH lo identifica como un trastorno «caracterizado por la combinación de un comportamiento hiperactivo y pobremente modulado con una marcada falta de atención y de continuidad en las tareas; existe una falta de persistencia en la actividades que requieren la participación de procesos cognitivos, tendencia a cambiar de actividades sin terminar las precedentes, y una actividad desorganizada y excesiva», lo cual «no afecta a la capacidad de comprender lo injusto del hecho, ni impide la capacidad de dirigir la actuación conforme a dicho entendimiento, pues si bien el trastorno examinado puede suponer una aminoración de los frenos para actuar en determinado sentido, el procesado, aunque esforzadamente, era capaz de rechazar la conducta gravemente lesiva realizada, máxime teniendo en cuenta que se trata de un hecho que no guarda relación intrínseca con el mencionado trastorno». No obstante, al final del Fundamento Jurídico Tercero, a modo de 
conclusión, se resalta la imposibilidad de sustentar una eximente completa o incompleta $^{55}$, dejando abierta la hipótesis de la atenuante analógica ${ }^{56}$.

C) No alusión al TDAH como posible circunstancia modificativa de la responsabilidad penal. Llama poderosamente la atención semejante grupo de sentencias, en las que podría haberse creado una línea argumental clara para modular la responsabilidad penal del imputado pero, por una u otra circunstancia, no se ha producido. En este sentido, conviene destacar la Sentencia de la Audiencia Provincial de Burgos 44/2012, de 2 de octubre [JUR 20121376015], donde, pese a presentar el imputado un diagnóstico clínico de trastorno por déficit de atención e hiperactividad por el que sigue tratamiento farmacológico y atención educativa específica en el contexto escolar, está aprendiendo a controlarse, se muestra más tranquilo y su pauta conductual actual resulta más adaptada, pese a necesitar fortalecer estrategias relacionadas con el autocontrol y la conducta prosocial, no se aduce nada al respecto como posible elemento motivador de la agresión, cuando por las características del hecho puede existir una correlación entre trastorno y agresión producida.

Del mismo modo, la Sentencia de la Audiencia Provincial de Madrid 898/2012, de 18 de diciembre [JUR 2013\24963], deja un margen de duda al respecto ya que aunque se corrobora la presencia del TDAH en el condenado, no parece que el trastorno guarde relación con los hechos imputados, no existiendo, en consecuencia, una convicción firme por parte del órgano judicial al respecto, sin motivación alguna, lo que podría suponer una vulneración del principio in dubio pro reo.

De otro lado, la Sentencia de la Audiencia Provincial 239/2011, de 13 de junio [JUR 2011 245879], recoge que los informes periciales contemplan la presencia de

\footnotetext{
${ }^{55}$ En particular, el Tribunal es algo más duro, refiriendo que se trata de una «pretensión que se considera verdaderamente absurda».

${ }^{56}$ Cuestión que no entra a desarrollar por carecer «de sentido práctico, pues la pena decidida ya está incursa en la mitad inferior».
} 
TDAH, trastorno de inestabilidad emocional de la personalidad de tipo impulsivo o límite, vinculado con un consumo perjudicial (abuso) de alcohol y de cocaína, estimando los peritos que la imputabilidad se vería afectada de un modo parcial si al trastorno impulsivo se le une el consumo de drogas o de alcohol, pero en este caso no consta que el procesado hubiera consumido recientemente cocaína.

D) Desconocimiento de las partes del proceso de la significación y efectos del TDAH. Se trata, como ya se ha referido, del supuesto más habitual en la planta jurisdiccional española, caracterizándose por el diagnóstico del TDAH del imputado pero un nulo tratamiento a sus posibles efectos, lo cual, en no pocas situaciones, podría otorgar una explicación a la comisión del delito. Semejante crítica no va dirigida exclusivamente a los jueces y magistrados, quienes a fin de cuentas juzgan el hecho ilícito, sino sobre todo a las partes implicadas en el proceso y los peritos intervinientes quienes, a instancias del órgano judicial, debieran informar de las connotaciones, efectos y consecuencias del trastorno, algo que, como demuestra la práctica, no acontece $^{57}$. Por ello, como puede corroborarse empíricamente, la hipótesis más repetida es la de enunciar que el imputado presenta TDAH, normalmente junto a otros trastornos, y proceder al análisis de uno de ellos -normalmente un trastorno de la personalidad-, llegando como mucho a realizar equiparaciones incorrectas entre trastornos -el más común TDAH y trastorno de la personalidad-, lo que no hace sino evidenciar su desconocimiento.

\footnotetext{
${ }^{57}$ Llegado a este punto, conviene recordar las reflexiones de Martínez Garay en virtud de las cuales la imputabilidad constituiría un complejo empírico-normativo en cuyo esclarecimiento concurrirían la competencia del perito y la del juez. Así, respecto del elemento biológico o psicológico, la intervención del juez se justificaría por la determinación de los hechos que realiza el perito en su dictamen, el cual ha de ser plausible pudiendo comprender por qué ha llegado a esa conclusión, marco teórico sobre el que se sustenta, correlación de los síntomas hallados con los que se describe al trastorno diagnosticado (...). Todo ello obliga a que el juez compruebe, en la medida en que su formación no especializada en ciencias de la psique se lo permita, la exhaustividad, coherencia y comprensibilidad del dictamen pericial. Del mismo modo acontecería con el criterio de la comprensión del hecho y la actuación conforme a esa comprensión, donde la práctica totalidad del peso científico recae en el perito, no quedando mucho margen para una valoración posterior del juez con arreglo a otros criterios no empíricos. En otras palabras, ¿Quién mejor que el perito para responder a la pregunta de si el acusado pudo comprender que el hecho era antijurídico y pudo gobernar según esa comprensión? Así pues, el penalista está obligado a llevar a cabo una clarificación de aquello sobre lo que se pide opinión al perito y una delimitación entre esto y el verdadero componente normativo de la imputabilidad (MARTÍNEZ GARAY, 1., La imputabilidad... cit., págs. 293-301).
} 
Por el contrario, también es cierto que conforme se avanza en el estudio jurisprudencial del tratamiento del TDAH por los Tribunales españoles se observa que semejante hipótesis va disminuyendo conforme avanzan las anualidades, siendo cada vez menores las tasas de desconocimiento, confusión o equiparación errónea del trastorno, pudiendo citar, a modo de ejemplo, a la Audiencia Provincial de Madrid como caso más paradigmático al respecto, en el sentido de la mayor presencia de resoluciones judiciales sobre TDAH en las que de manera más o menos adecuada dan una correcta interpretación -o al menos lo intenta- del trastorno y su vinculación con los fenómenos delictivos.

No obstante, como ejemplos paradigmáticos del grupo de sentencias que conforman el colectivo citado, se refieren las siguientes manifestaciones jurisprudenciales:

d1) Auto de la Audiencia Provincial de Madrid 724/2011, de 31 de octubre [JUR 2012\17413], donde el recurrente intenta evitar el ingreso en prisión por la presentación de un trastorno por déficit de atención e hiperactividad y trastorno antisocial de la personalidad con dependencia de sustancias tóxicas y alcohol, presentes antes, durante y después de la comisión del ilícito penal, de los cuales evoluciona favorablemente, frustrando el ingreso en prisión los fines de prevención y reinserción social. Sin embargo, el Tribunal rechaza semejante hipótesis en tanto ni el penado ni su defensa alegaron en su momento la existencia de circunstancia modificativa alguna, ahora resaltan la presencia del TDAH y el trastorno antisocial, por lo que semejante parámetro no ha sido contrastado por un médico forense y, en consecuencia, dicho diagnóstico no justifica la sustitución de la pena, sin perjuicio de que el penado pueda recibir la asistencia psicológica que precise en el seno de la prisión.

d2) Auto de la Audiencia Provincial de Guipúzcoa 108/2011, de 29 de marzo [JUR 2011 2295289], donde el condenado presenta TDAH y consumo de sustancias 
tóxicas desde los trece años. En el Auto de referencia se decreta la suspensión de la pena impuesta y continuación de su tratamiento en el Centro de Salud Mental, el cual se refiere únicamente al consumo de drogas, dejando de lado toda referencia al trastorno por déficit de atención e hiperactividad, con las implicaciones que esto puede tener tanto para el propio consumo de tóxicos como para futuros comportamientos criminales, los cuales no podrá cometer en un plazo de tres años para cumplir con las condiciones de la sustitución.

d3) La Sentencia de la Audiencia Provincial de Barcelona, de 5 de noviembre de 2009 [JUR 20091468066], recoge un juicio de valor llevado a cabo por el Tribunal absolutamente criticable ya que, tras concluir que el imputado no presenta realmente un trastorno por déficit de atención en hiperactividad o trastorno por déficit de atención, de acuerdo con lo manifestado por los peritos, no suponiendo en modo alguno una disminución en el menor de sus facultades volitivas o intelectivas, pues tal como se puso de relieve, importantes personajes de la historia lo padecían y en modo alguno han incurrido en una actividad criminal, sino todo lo contrario, han hecho grandes aportaciones a la sociedad, manifestando también el perito que las personas que sufren tales déficits evolucionan hacia la normalidad.

\section{Conclusiones.}

El momento de observación de la imputabilidad debe apreciarse en el instante de comisión del delito para verificar si, según la opción mantenida, la persona presenta las facultades psíquicas mínimas requeridas para, o bien valorar y comprender la ilicitud del hecho y actuar en los términos requeridos por el ordenamiento jurídico, o poder ser motivado en sus actos por los mandatos normativos. 
En mi opinión, y así se ha manifestado la Jurisprudencia, como ya se ha detallado, la persona que presenta TDAH es en todo momento plenamente consciente de la ilicitud del hecho cometido, no existiendo, como regla general, una afectación relevante en su ámbito cognitivo; debiendo reconducir necesariamente la hipotética afectación de la imputabilidad hacia la esfera volitiva, sobre la cual tanto el Tribunal Supremo como las distintas Audiencias Provinciales, quitando un supuesto concreto en el que aplica una eximente incompleta, se han decantado por la plena imputabilidad de los sujetos que presentan TDAH, llegando, como mucho, a verificar la presencia de una atenuante analógica de alteración psíquica basada en el artículo $21.7^{\circ}$ del Código Penal en relación con el $21.1^{\circ}$ y el $20.1^{\circ}$, basadoo principalmente en la dificultad de controlar los impulsos que presenta el sujeto con TDAH; esto es, la persona sería plenamente consciente de los hechos ilícitos cometidos y el reproche penal que comportan pero se muestra incapaz de controlar los impulsos, lo cual debiera tener necesariamente su reflejo en una atenuación punitiva.

Sin embargo, llegados a este punto, se hace necesario otorgar un tratamiento diferenciado a las subtipologías de TDAH existentes por cuanto la afectación sobre la capacidad volitiva es distinta por las propias particularidades de cada subcategoría. Así, por ejemplo, la afectación de la capacidad volitiva del subtipo impulsivo es mayor dada la clara imposibilidad de controlar los impulsos que respecto del inatento, en quien únicamente concurre, que no es poco aunque no muy relevante para la imputabilidad, una falta de atención con determinados estímulos; frente al hiperactivo en sentido estricto, para quien no aprecio afectación alguna ya que la incidencia del TDAH en el comportamiento criminal no está tan orientada al delito en sí como a los factores que pudieran producirlo o desencadenarlo. Por último, el combinado, al concurrir dos subtipos anteriores, reuniría, de manera genérica, los grados referidos para cada uno de los subgrupos. 
A mi juicio, ésa es la línea argumental que debe seguirse para el tratamiento de la imputabilidad de las personas que presentan TDAH, si bien entiendo que deben realizarse una serie de apreciaciones:

- Como se ha dicho, pero conviene resaltar, junto al TDAH cohabitan, en no pocas ocasiones, comorbilidades, las cuales dificultan sobremanera su diagnóstico. Este hecho no debe justificar la ausencia en la verificación de si el TDAH pudo motivar el comportamiento ilícito del sujeto sino justamente lo contrario: los juzgadores no deben otorgar una explicación del grado de imputabilidad de la persona sobre criterios basados en trastornos, enfermedades o adicciones que crean similares al TDAH o simplemente reconducir el análisis de la culpabilidad hacia la comorbilidad por haber sido muy estudiada y cuyos parámetros de actuación sean sobradamente conocidos. Para cumplimentar esta labor se encuentran los peritos, quienes no sólo deben valorar al imputado sino auxiliar al juzgador en todo aquellos para lo que sean requeridos.

- Particularizando sobre el TDAH y teniendo presente que cada ilícito debe ser analizado en el momento de comisión de los hechos delictivos pueden establecerse las siguientes reglas generales que operarán sobre la imputabilidad como criterios genéricos: i) la afectación de la capacidad volitiva del subtipo impulsivo es la mayor que puede apreciarse, dada la clara imposibilidad de controlar los impulsos y, por ende, sus actos, llegando a derivar en actos agresivos, ante lo cual debiera plantearse la presencia de la anteriormente citada atenuante analógica; ii) el inatento, en quien únicamente concurre, que no es poco aunque no muy relevante para la imputabilidad, una falta de atención con determinados estímulos, lo que genera una desatención en la actividad principal que se encuentra desarrollando, encontrándose en una situación intermedia entre el impulsivo y el hiperactivo en sí, que genéricamente deberá resolverse a favor de su plena imputabilidad; iii) el hiperactivo en sentido estricto, para quien no aprecio afectación alguna ya que la incidencia del TDAH en el comportamiento criminal no está tan orientada al delito en sí como a los factores que pudieran producirlo o desencadenarlo, siendo, por ello, plenamente imputable; y iv) el 


\section{Doctrina y Jurisprudencia}

combinado, el cual incluiría la categoría más amplia y compleja de encuadrar al concurrir en él dos subtipos anteriores, por lo que habría que verificar los caracteres descritos y ponerlos en consideración de manera conjunta.

En definitiva, gráficamente podría esquematizarse el citado nivel de afectación de la imputabilidad y los efectos derivados de la siguiente manera:

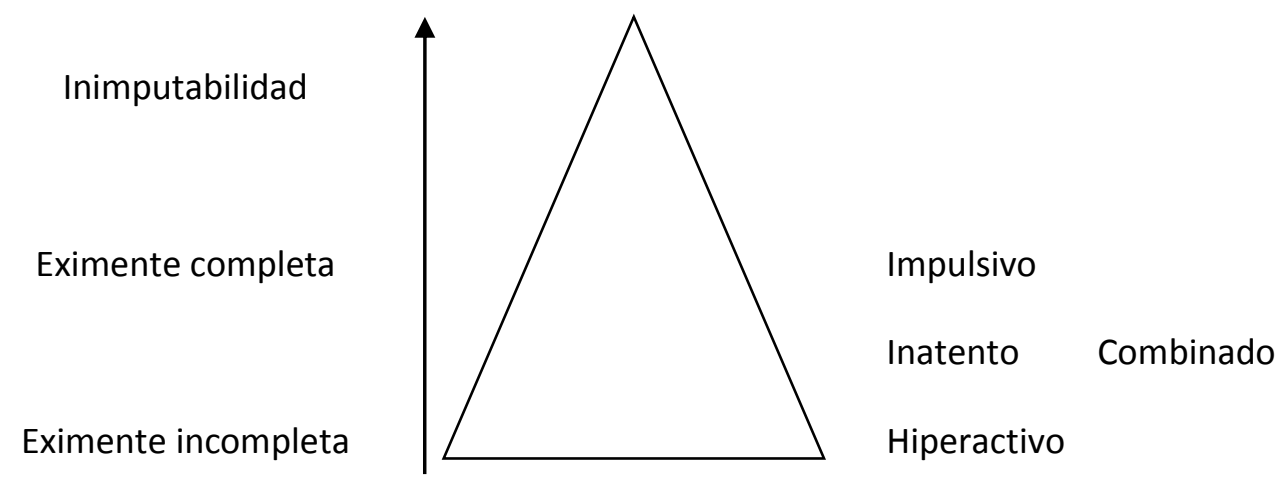

